\title{
Assessment of load factors affecting women farmers in maize production operations
}

Harshita Jain, Suman Singh and Hemu Rathore

Received: 26.11.2017; Revised: 26.03.2018; Accepted: 13.04.2018

See end of the paper for authors' affiliations

Harshita Jain

Department of Family Resource Management, College of Home

Science, Maharana Pratap

University of Agriculture and

Technology, Udaipur (Rajasthan)

India

Email : jainharshita24@gmail.

com
ABSTRACT : Women in agriculture play a vital role in wide range of activities, thereby contributing to sustainable agricultural development. To achieve inclusive agricultural growth, empowering women by having comprehensive understanding about work participation, gender issues, drudgery and health and nutritional status is necessary. The study was conducted in tribal development block of Udaipur district namely Kherwara. Data were collected from 60 tribal farm families by a pre-designed interview schedule. Different socio-personal characteristics revealed that all of the tribal women were in 20 to 50 years age group, belonged to nuclear and not heading the family, illiterate and engaged in all type of agricultural activities and rearing small hesrd of livestock. Based on the study it was seen that there were six load factors which affected women's work efficiency in maize production operation. The data explained that average MSD Load factor was highest (3.37/5) followed by Repetitive Strain Load (3.04/5), Physical Load (2.70/5), Time Load (2.18/5), Posture Load (1.92/5) and Physiological Load (1.80/5).

KEY WORDS: Tribal women, Gender participation, Maize production system, Load factors, Physical load, Repetitive strain load, MSD load, Posture load

- HOW TO CITE THIS PAPER : Jain, Harshita, Singh, Suman and Rathore, Hemu (2018). Assessment of load factors affecting women farmers in maize production operations. Asian J. Home Sci., 13 (1) : 122-127, DOI: 10.15740/HAS/AJHS/13.1/122-127. Copyright@ 2018: Hind Agri-Horticultural Society. 